\title{
PROPOSTA DE ANÁLISE DE DESEMPENHO FINANCEIRO EM PEQUENAS EMPRESAS RURAIS: O CASO DA PISCICULTURA
}

\author{
Marcelo Guilhermino Petersen* \\ Timóteo Ramos Queiroz** \\ David Ferreira Lopes Santos*** \\ Élton Eustáquio Casagrande ${ }^{* * * *}$ \\ Adriano dos Reis Lucente ${ }^{* * * * * *}$
}

RESUMO: Este estudo tem por objetivos propor e avaliar um modelo de gestão financeira para a pequena empresa rural da piscicultura na expectativa de trazer informações para o processo decisório deste setor específico do agronegócio, e que, igualmente, permita comparar o seu desempenho com outras atividades do mercado. Com mais de 5,5 milhões de hectares de água doce, o Brasil é responsável por $0,76 \%$ da produção aquícola mundial, sendo que a informalidade da atividade e dos seus processos de decisão é uma realidade para o caso brasileiro, o que restringe uma melhor e maior exploração dos recursos potenciais do país. Os estudos empíricos para este setor concentram-se em avaliações econômicas de projetos específicos, sendo um desafio e até um desconhecimento o potencial de rentabilidade da empresa inserida na aquicultura no Brasil. O caso foi estudado durante seis meses com visitas in loco, observações participantes e análise de documentos. A propriedade está situada no Estado do Mato Grosso do Sul e atua na produção de tilápias (Oreochromis Niloticus), em estruturas de tanque-rede com capacidade nominal de 1.930 ton/ano. O resultado da pesquisa abrange desde uma estrutura metodológica para a identificação, reconhecimento e apuração dos gastos da propriedade a partir dos lotes de produção até a consolidação em uma estrutura de fluxo de caixa e controle de patrimônio. Esta estrutura de informações permite a

\footnotetext{
"Mestre em Administração na (UNESP FCAV) Campus de Jaboticabal. Pós-Graduado em Contabilidade, Governança e Controle pela Universidade de São Paulo (USP). Área de atuação (Gestão de Organizações Agroindustriais), Brasil. E-mail: marceloguilherminopetersen@gmail.com

** Doutor em Engenharia de Produção pela Universidade Federal de São Carlos, Departamento de Administração, UNESP - Universidade Estadual Paulista Júlio de Mesquita Filho - Faculdade de Ciências e Engenharia, Campus de Tupã, Brasil.

*** Pós-Doutor e Doutor em Administração de Empresas pela Universidade Presbiteriana Mackenzie, Docente Assistente Doutor, Departamento de Economia, Administração e Educação, UNESP/FCAV, Brasil.

${ }^{* * * * *}$ Pós-Doutor pela Universidade Federal do Rio de Janeiro, Doutor em Economia de Empresas pela Fundação Getúlio Vargas. Professor Assistente Doutor da Universidade Estadual Paulista Júlio de Mesquita Filho, Faculdade de Ciências e Letras, Departamento de Economia, Brasil.

***** Doutor em Engenharia de Produção pela Universidade Federal de São Carlos, Docente Assistente Doutor, Departamento de Economia, Administração e Educação, UNESP/FCAV, Brasil.
} 
gestão do orçamento, do caixa e da análise do desempenho por meio de indicadores para a propriedade rural de piscicultura.

PALAVRAS-CHAVE: Agronegócio; Aquicultura; Desempenho financeiro; Oreochromis Niloticus; Tanque-Rede.

\section{ANALYSIS OF FINANCIAL PERFORMANCE IN SMALL RURAL FARMS: FISH FARMING}

ABSTRACT: Current study proposes and evaluates a financial management model for small rural fish farming companies to provide information for decision taking within this type of agribusiness, and compares its performance with other activities on the market. Featuring 5.5 million hectares of fresh water, Brazil has $0.76 \%$ of aquaculture production worldwide. The informality of such activity and decision taking are peculiar to Brazil, restricting a better and greater exploitation of the country's potential resources. Empirical studies have focused on economic evaluations of specific projects. However, the income of such fish farming companies in Brazil is a challenge and still unknown. The case was analyzed during six months with visits on the spot, participating observations and analysis of documents. The fish farm lies in the state of Mato Grosso do Sul and produces Nile tilapias (Oreochromis niloticus) in net tanks, with a nominal capacity of 1930 tons/year. Results range from methodological structuring to identification, acknowledgement and expenditure through production plots till the consolidation within a structure of cash flow and property control. The above information allows budget administration, cash and performance by indexes for fish farming.

KEY WORDS: Agribusiness; Aquiculture; financial performance; Oreochromis niloticus; Net tanks.

\section{INTRODUÇÃO}

O agronegócio é responsável pela integração de diversos setores da economia e sua participação no Produto Interno Bruto (PIB) brasileiro tem aumentado nos últimos anos (CORRÊA; KLIEMANN NETO; DENICOL, 2016).

Os múltiplos estudos que têm sido realizados para avaliação econômica de projetos e investimentos nesse setor (MACFADYEN et al., 2012; AZEVEDO et al., 2015; EL-SAYED; DICKSON; EL-NAGGAR, 2015; DE BEZERRA et al., 2016) são 
em geral, específicos, oriundos da área tecnológica para avaliação econômica de melhoramento genético (DOMÍNGUEZ-CASTANEDO et al., 2014) ou para dietas e sistemas de produção de peixes (ANYADIKE; MBAJIORGU; AJAH, 2015; EMERY et al., 2016).

Ressalta-se que o Brasil é um dos principais países com avaliação econômica de projetos na piscicultura nas bases de dados SCOPUS e Web of Science, contudo, não se evidenciou estudos quanto aos modelos de gestão ou avaliação de empresas neste setor.

Embora as análises de investimentos constituam um dos instrumentos de decisão mais representativos na gestão financeira, a viabilidade do empreendimento não deve se basear exclusivamente na seleção de projetos com valor presente líquido positivo, mas necessita incorporar estudos de alavancagem, estruturas de liquidez, gestão do capital de giro e gestão baseada em desempenho e criação de valor (ASSAF NETO, 2009; DAMODARAN, 2012).

$\mathrm{Na}$ área financeira os modelos de gestão e suas conexões com os procedimentos gerenciais são genéricos e precisam ser adaptados a distintas realidades, o que torna as experiências empíricas fundamentais para compreensão das aplicações e dos limites da teoria em cada contexto investigado (SANTOS, 2015).

Em decorrência da elevada informalidade existente na gestão da empresa rural, em especial na piscicultura, a motivação inicial do estudo foi responder ao seguinte questionamento: Como estruturar um modelo de gestão financeira para a piscicultura?

Diante do exposto, este estudo tem dois objetivos que são: propor e avaliar um modelo de gestão financeira para a pequena empresa rural da piscicultura na expectativa de trazer informações para o processo decisório deste setor específico do agronegócio, e, igualmente, permita comparar o seu desempenho com outras atividades do mercado.

Assim, além da significativa contribuição teórica, o artigo discute uma ferramenta que pode ser utilizada por pequenos e médios produtores rurais na atividade, cuja gestão ainda ocorre de forma informal ou sem processos de controles definidos. Não obstante, alça indicadores para a atividade que poderão ser estendidos ou replicados, a fim de criar mecanismos de benchmarking para o desempenho 
econômico e financeiro da atividade da piscicultura em tanques redes no Brasil.

Para alcançar os objetivos deste estudo, o artigo está estruturado em mais três seções. A segunda seção aborda os Materiais e Métodos que subsidiaram a realização da pesquisa. Na sequência, o artigo traz os resultados da pesquisa e a discussão quanto às evidências encontradas no caso estudado. A quarta seção apresenta as considerações finais quanto às implicações gerenciais e teóricas do estudo, além de pontuar as limitações da pesquisa e de seus resultados como também a proposição de estudos futuros.

\section{MATERIAL E MÉTODOS}

Este estudo caracteriza-se como uma pesquisa aplicada, a partir de um estudo de caso intencional, não probabilístico, exploratório e qualitativo, cujos resultados permitem identificar pontos relevantes para a construção do modelo de gestão financeira da empresa estudada.

O primeiro passo para elaborá-lo foi realizar uma revisão da literatura sobre desempenho financeiro e análise financeira das empresas do agronegócio, com foco na piscicultura, em portais de periódicos científicos, livros e sites de órgãos governamentais. Esta revisão identificou predomínio de análises muito específicas e possibilitou expressar a relevância de ampliar o conhecimento sobre a temática em função da identificação de lacunas teórico-práticas.

Posteriormente, fez-se uma revisão bibliográfica sistematizada (RBS), com base nas referências metodológicas apresentadas em alguns estudos e nos principais textos da área de administração financeira (WEBSTER; WATSON, 2002; CONFORTO; AMARAL; SILVA, 2011; GONZÁLEZ; TOLEDO, 2012; PIGOSSO; ROZENFELD, 2012). Para desenvolvimento deste estudo foram seguidas ainda as recomendações metodológicas de Gil (2002) para elaboração de um estudo de caso.

Intenciona-se que o modelo proposto neste estudo atenda ao seu propósito de gerir financeiramente esta organização e, posteriormente, novas empresas que o adotarem, respeitando sempre o contexto, características próprias e intervalo temporal.

A empresa estudada está localizada no Estado do Mato Grosso do Sul, 
no reservatório da Usina Hidroelétrica (UHE) de Ilha Solteira. Evidentemente a confidencialidade dos dados sigilosos em relação à empresa para o uso exclusivamente acadêmico foram preceitos fundamentais desse trabalho. Foi ofertado à empresa um termo de responsabilidade, no qual os autores comprometeram-se com as questões éticas da pesquisa quanto à identificação de profissionais e informações sigilosas da empresa.

O período da pesquisa empírica compreendeu os meses de janeiro a junho de 2017, sendo realizadas quatro (04) visitas in loco com um total de 44 horas de acompanhamento das atividades administrativas e de produção, os registros foram anotados em caderno de campo.

Providenciou-se também registros fotográficos da atividade e análise de documentos fiscais, contratuais e comerciais disponíveis, caracterizando a pesquisa como documental. Entende-se que as diferentes fontes de informações são necessárias para a realização de um estudo de caso, a fim de melhor compreender o fenômeno de interesse (GODOY, 1995).

Não obstante, torna-se necessário que tenham maior nível de imparcialidade possível; neste sentido, teve-se como estratégia metodológica a participação e o envolvimento direto de dois pesquisadores com o caso estudado e os autores mantinham rotina de reunião com os primeiros para analisar as evidências e discutir resultados e alternativas para o modelo de gestão.

Em que pese as dificuldades e limitações deste tipo de estudo, julga-se que as alternativas escolhidas foram suficientes para que a atividade financeira realizada informalmente pudesse ser compreendida de forma associada à estrutura produtiva da atividade de piscicultura de produção de tilápias em tanques-redes com profundidade.

\section{RESULTADO E DISCUSSÃO}

A realidade empírica dos pequenos e médios produtores rurais é de elevada informalidade nos seus processos de gestão e isso não é diferente na área da piscicultura (FRANÇA, 2012).

Dessa forma, para construção do modelo apresentado neste estudo, avalia- 
se previamente o grau de controle das informações financeiras com base em duas principais estruturas: a primeira estrutura proveniente do balanço patrimonial (BP), da demonstração do resultado do exercício (DRE) e da demonstração do fluxo de caixa (DFC), porém diante da realidade do pequeno e do médio produtor rural, o artigo sugere a utilização de uma segunda estrutura, o livro-caixa rural.

Ambos os procedimentos são importantes, uma vez que a informalidade existente na gestão das propriedades rurais e a terceirização do serviço contábil, com foco somente em aspectos fiscais, podem comprometer a elaboração de um modelo de gestão, o que torna necessário avaliar a priori as fontes de informação.

De fato, o modelo tem complexidade, mas ele é mais simplificado que um processo de controladoria de empresas convencionais, inclusive poder ser operacionalizado dentro de uma planilha de Microsoft Excel, quando, neste caso em que os eventos econômicos realizados serão extraídos do livro-caixa rural (base de dados para a confecção do fluxo de caixa), que é o caso das pequenas e médias empresas rurais.

A dificuldade principal é na informalidade do tratamento dos registros operacionais e financeiros. Isso requer mudança de cultura e a instrumentalização dos produtores com práticas assertivas; sendo assim, esse modelo contribui para demonstrar a importância dos registros e da necessidade de modelos que o auxiliem na tomada de decisão.

Por fim, pode-se incluir uma limitação em razão do aspecto cultural da atividade e sugerir a necessidade do apoio de atividades de extensão rural a partir de universidades, institutos de pesquisa, órgãos de fomento à atividade como SENAR e a EMBRAPA e organizações sociais e organizações associativas.

De forma concomitante, de posse desses indicadores, independentemente do regime de tributação (pois os indicadores sugeridos no decorrer do trabalho contemplam ambos os regimes de tributação) e tendo como base as demonstrações contábeis e financeiras da propriedade rural de pequeno porte na piscicultura, estrutura-se um modelo de gestão financeira, tendo em vista aspectos apontados na literatura. 


\subsection{DESEMPENHO FINANCEIRO COM BASE NO BP, DRE, DFC}

As empresas do agronegócio no seu processo de abertura, ou durante sua continuidade, podem, respeitando o exercício fiscal, optar pela tributação com base no lucro real, lucro presumido e até pelo simples nacional.

Mediante isto, as empresas que forem optantes por estes regimes de tributação irão produzir documentos financeiros e contábeis geralmente conhecidos, como o balanço patrimonial, a demonstração do resultado do exercício e da demonstração de fluxo de caixa, dentre outros. Sugere-se, então, analisar as variáveis de endividamento e investimento de um modelo tradicional extraídas destes documentos. As variáveis sugeridas para o quadro geral de indicadores de gestão financeira desenvolvido envolvem as seguintes dimensões: i) endividamento; ii) investimento; iii) necessidade do capital de giro e liquidez; iv) solvência; v) rentabilidade; vi) risco (ASSAF NETO, 2009; DAMODARAN, 2012; SANTOS, 2015).

\subsubsection{Endividamento}

O sistema de crédito público e privado brasileiro disponibiliza diferentes linhas de financiamento aos produtores rurais com juros subsidiados e, em alguns casos, subvenção econômica (FARIA; SANTOS, 2014).

Os financiamentos, de forma geral, podem ser divididos em duas vertentes: crédito para custeio e crédito para investimento, ambos os casos exigem do produtor ou administrador rural cuidado na sua avaliação quanto à adequação das linhas de financiamento aos seus fins, a avaliação se o custo financeiro é inferior ao retorno do investimento e se o fluxo de pagamento é compatível com o fluxo de caixa da propriedade.

Esta análise é de suma importância para avaliar o potencial do crédito de custeio necessário para alavancar os resultados do produtor. As variáveis para a análise do endividamento no modelo de gestão financeira sugeridas para a piscicultura estão apresentadas no Quadro 1. 
QUADRO 1. Variáveis sugeridas para análise

\begin{tabular}{|c|c|}
\hline Varlável do Modelo Proposto - Endividamento & Fonte de Dados \\
\hline Endividamento $=\frac{\text { Total de Empréstimos e Financiamentos }}{\text { Patrimônio Líquido }}$ & $\begin{array}{c}\text { Balanço } \\
\text { Patrimonial } \\
\text { DRE }\end{array}$ \\
\hline Estrutura de Capital $=\frac{\text { Investimentos }}{\text { Patrimônio Liquido }} \%$ & $\begin{array}{c}\text { Balanço } \\
\text { Patrimonial } \\
\text { DRE }\end{array}$ \\
\hline $\begin{array}{c}\text { Composição do Endividamento } \\
\text { Total de Empréstimos e Financiamentos }\end{array}$ & $\begin{array}{c}\text { Balanço } \\
\text { Patrimonial }\end{array}$ \\
\hline $\begin{array}{c}\text { Qualidade de Alavancagem do Crédito Custeio } \\
\text { Retorno da Margem de Contribuição }\end{array}$ & DFC \\
\hline Custo do Crédito Rural de Custeio & \\
\hline
\end{tabular}

Fonte: Adaptado (MATIAS, 2007; ALVES, 2009; SANTOS, 2015).

No que se refere à alavancagem do crédito de custeio, espera-se que o quociente da relação prevista seja maior que 1, pois significará que o produtor conseguiu aumentar o ganho da sua propriedade para diluir os recursos financiados no custo fixo; do contrário, haverá transferência de rentabilidade da propriedade para a instituição financeira.

Uma vez concebido o projeto de investimento e realizada a apuração do valor atual líquido, a exequibilidade do projeto depende da capacidade de gerenciamento.

\subsubsection{Investimento}

Entende-se que todos os indicadores teóricos previstos podem ser aplicados na piscicultura. A ênfase neste estudo recai sobre a eficácia dos ativos em imobilizados. A razão do indicador incide sobre as características da produção que necessita de área, tanques e equipamentos específicos, de modo que, em propriedades rurais de pequeno e médio porte, significativos espaços podem não ser utilizados adequadamente para a piscicultura em função da necessidade de disponibilizar recursos para investimentos imobilizados.

O Quadro 2 também apresenta as variáveis sugeridas para análise dos investimentos. 
QUADRO 2. Variáveis sugeridas para análise

\begin{tabular}{|c|c|}
\hline Variável do Modelo Proposto - Investimento & Fonte de Dados \\
\hline Eficácia dos Ativos $=\frac{\text { Receitas }}{\text { Ativo Total }}$ & $\begin{array}{c}\text { Balanço } \\
\text { Patrimonial } \\
\text { DRE }\end{array}$ \\
\hline Eficácia dos Ativos Dedicados $=\frac{\text { Receita }}{\text { Ativo Total Dedicado }}$ & $\begin{array}{c}\text { Balanço } \\
\text { Patrimonial DRE }\end{array}$ \\
\hline
\end{tabular}

Fonte: Adaptado (MATIAS, 2007; ALVES, 2009; SANTOS, 2015).

Assim, torna-se importante avaliar de forma específica a eficácia dos investimentos de fato utilizados, inclusive para efeitos comparativos com o total.

\subsubsection{Indicadores de capital de giro e liquidez}

Os indicadores de capital de giro apresentados (Quadro 3) são relevantes, mas o emprego desses indicadores pode não ser suficiente à gestão de curto prazo se não forem considerados os ativos biológicos como fonte de aplicação de capital circulante.

QUADRO 3. Variáveis sugeridas para os indicadores

\begin{tabular}{|c|c|}
\hline Varrável do Modelo Proposto - Giro e Liquidez & Fonte de Dados \\
\hline Necessidade de Capital de Giro $=\mathrm{CF} \times \frac{\text { Receita }}{360}$ & $\begin{array}{c}\text { Balanço Patrimonial } \\
\text { DRE }\end{array}$ \\
\hline Equilíbrio Financeiro $=\frac{\text { Capital Circulante Líquido }}{\text { Receita }}$ & $\begin{array}{c}\text { Balanço Patrimonial } \\
\text { DRE }\end{array}$ \\
\hline
\end{tabular}

Fonte: Adaptado (MATIAS, 2007; ALVES, 2009; ASSAF NETO, 2009; SANTOS, 2015).

Desconsiderar o investimento no ativo biológico acarretará uma subavaliação na necessidade de capital de giro e na liquidez corrente da propriedade 
e uma 'superavaliação' da liquidez seca. O indicador de cobertura de juros oferece ao gestor uma visão dos efeitos da variação de receitas, custos e despesas e a capacidade de saldar os compromissos financeiros. Nas atividades de gestão da empresa rural pouca importância têm os indicadores financeiros. A ênfase nos aspectos operacionais e cuidados para o êxito da atividade pode conduzir a gerência por um caminho de uso excessivo de recursos para o desempenho operacional. O efeito é reduzir a margem de contribuição, elevar o ponto de equilíbrio financeiro e, por consequência, reduzir a capacidade de cobertura de juros. Os riscos causados pela necessidade de refinanciamento, dadas as taxas de juros elevadas do sistema de crédito, podem prejudicar o investimento e a própria gestão operacional da atividade. Logo, a gestão da empresa rural deve ter como prioridade uma meta para o grau de cobertura de juros e conduzir a gestão dos indicadores operacionais a partir da meta aqui definida.

\subsubsection{Indicadores de rentabilidade e risco}

Os indicadores de rentabilidade e lucratividade (Quadro 4) são resultados de uma acurada classificação e controle dos custos e despesas segundo sua natureza fixa e variável. Assim, será possível determinar o nível de receita a ser gerada e/ou a quantidade (kg ou ton) de produção necessária para o alcance do retorno desejado. Por outro lado, a mensuração do risco não será possível com base nas condições de mercado, pois não há, no contexto brasileiro, empresas de piscicultura listadas em bolsa de valores. 
QUADRO 4. Variáveis sugeridas para os indicadores

\begin{tabular}{|c|c|}
\hline Varlável do Modelo Proposto - Rentabilidade e Risco & Fonte de Dados \\
\hline Margem Bruta $=\frac{\text { Lucro Bruto }}{\text { Receita }}$ & $\begin{array}{l}\text { DRE } \\
\text { DFC }\end{array}$ \\
\hline Margem EBIT $=\frac{\text { EBIT }}{\text { Receita }}$ & DRE \\
\hline DFC \\
\hline Return on Investment $=\frac{\text { NOPAT }}{\text { Investimento }}$ & $\begin{array}{c}\text { Balanço Patrimonial } \\
\text { DRE }\end{array}$ \\
\hline
\end{tabular}

Fonte: Adaptado (MATIAS, 2007; ALVES, 2009; ASSAF NETO, 2009; SANTOS, 2015).

Neste cenário, postulam-se como risco duas variáveis de característica endógena e exógena: as volatilidades de receita e o EBIT, com base nas quais o produtor poderá avaliar se as principais variações são de natureza associada ao mercado (receita) ou à eficiência das suas operações (EBIT).

Contudo, são indicadores que deverão ser analisados com muita cautela em virtude do grande número de variáveis que podem influenciar o resultado agregado da receita e do EBIT.

Não obstante, não é aconselhável utilizar somente o custo dos créditos rurais, pois não financiam $100 \%$ dos investimentos em imobilizado e as taxas são subsidiadas. A volatilidade da receita e o retorno dos investimentos são os indicadores essenciais de conhecimento do empresário rural, em conjunto com os demais selecionados.

\subsection{DESEMPENHO FINANCEIRO ATRAVÉS DO LIVRO-CAIXA RURAL}

Da mesma forma que as empresas do agronegócio no seu processo de abertura, ou durante sua continuidade, podem, respeitando o exercício fiscal, optar pela tributação com base no lucro real, lucro presumido e até no simples nacional, estas empresas podem, também, optar pela tributação como pessoa física, transportando os resultados apurados no livro-caixa rural ao término do exercício fiscal. Neste caso, mesmo que esta opção não produza o conjunto de demonstrações 
contábeis que as empresas com CNPJ geralmente possuem, o resultado da exploração da atividade rural, quando realizado mediante este tipo de escrituração, seja manual, seja eletrônica, abrange, em geral, as receitas; as despesas de custeio; os investimentos; e os demais valores que integram a atividade rural.

No entanto, diante da limitação imposta mediante a documentação produzida por esta opção de escrituração através do livro-caixa rural, as variáveis sugeridas ficam em número reduzido em relação àquelas produzidas pelas empresas optantes pela tributação do lucro real, lucro presumido ou simples nacional (BP, DRE, DFC).

Dessa forma, as variáveis sugeridas no painel de indicadores de gestão financeira envolvem as seguintes dimensões: a) rentabilidade; b) endividamento; c) liquidez e solvência (ASSAF NETO, 2009; SANTOS, 2015) e podem ser extraídas da estrutura sugerida do fluxo de caixa da piscicultura. Os indicadores sugeridos estão apontados no Quadro 5.

Diante disso, como o referido artigo se posiciona, como um desenvolvedor tecnológico para a obtenção de dados provenientes destas escriturações das pequenas empresas da piscicultura, sugere-se, então, um modelo que contenha as variáveis necessárias para a devida análise do desempenho financeiro destas empresas com base no fluxo de caixa construído através dos lançamentos escriturados no livrocaixa rural.

Sugere que o produtor siga o modelo da Receita Federal na escrituração dos eventos ocorridos, e que estes sejam lançados na sequência $\left(1^{\circ}\right.$ Receita; $2^{\circ}$ Despesa dedutível; $3^{\circ}$ Despesa não dedutível; $4^{\circ}$ Receita ou Despesa de antecipação de contratos negociados) (SECRETARIA DA RECEITA FEDERAL DO BRASIL, 2017), tanto no livro-caixa rural, quanto na planilha do modelo proposto e desenvolvido neste trabalho.

Por considerar a característica do processo produtivo da piscicultura, iniciar a construção da primeira parte (das três que compõem o fluxo de caixa) pelo fluxo de caixa operacional (FCO) através dos lotes de produção

Construir o desempenho através dos lotes de produção quantifica e demonstra seu resultado operacional. Esta estratégia avança trazendo contribuições para o repasse dos custos aos lotes, melhorando a gestão financeira, a tomada de decisões por parte dos piscicultores, pois divide os custos operacionais, do custo do investimento e financiamento. 
QUADRO 5. Variáveis sugeridas dos indicadores para análise

\begin{tabular}{|c|c|}
\hline Variável do Modelo Proposto - Rentabilidade & Fonte de Dados \\
\hline $\mathrm{ROI}=\frac{\text { Fluxo de Caixa Operacional }}{(\Delta \text { Investimento }+ \text { Investimento o })}$ & Livro Caixa Rural \\
\hline Margem Operacional $=\frac{\text { Fluxo de Caixa Operacional }}{\text { Receita }}$ & Livro Caixa Rural \\
\hline Margem sobre a Venda $=\frac{\text { Lucro Líquido }}{\text { Receita }}$ & Livro Caixa Rural \\
\hline Margem Líquida do Lote $=\frac{\text { Margem de Contribuição }}{\text { Quantidade ou Unidade }}$ & Livro Caixa Rural \\
\hline Variável do Modelo Proposto - Endividamento e Liquidez & Fonte de Dados \\
\hline Retorno da Margem de Contribuição $=\frac{\text { Margem de Contribuição }}{\text { Receita }}$ & Livro Caixa Rural \\
\hline Comprometimento do caixa com a dívida $=\frac{\text { Financiamento }+(\Delta \text { Financiamento })}{\text { Fluxo de Caixa Operacional }}$ & Livro Caixa Rural \\
\hline Ponto de Equilíbrio $=\frac{\{\text { Custo Financeiro }+[\text { receita } * 0,20(\mathrm{IR}+\text { CSLL })]\}}{\frac{\text { Margem de Contribuição }}{\text { Quantidade ou Unidade }}}$ & Livro Caixa Rural \\
\hline
\end{tabular}

Fonte: Adaptado (ASSAF NETO, 2009; SANTOS, 2015).

Em seguida, paralelamente à orientação sequencial da Receita Federal para os lançamentos dos eventos ocorridos - receita/despesa dedutível/despesa não dedutível/receita ou despesa de antecipação de contratos negociados, elabora-se o filtro para o devido registro das receitas em planilha específica e escritura-se os dados pertinentes a cada lote e conta.

A soma dos lotes de produção então construirá o fluxo de caixa operacional. A escrituração dos eventos realizados relativos aos investimentos e aos financiamentos é lançada também no fluxo (segunda e terceira partes) para que se possa mensurar sua capacidade real de geração de caixa.

A Figura 1 demonstra o fluxo de caixa sugerido com as dimensões operacional, investimento e financiamento e traz os resultados consolidados. 


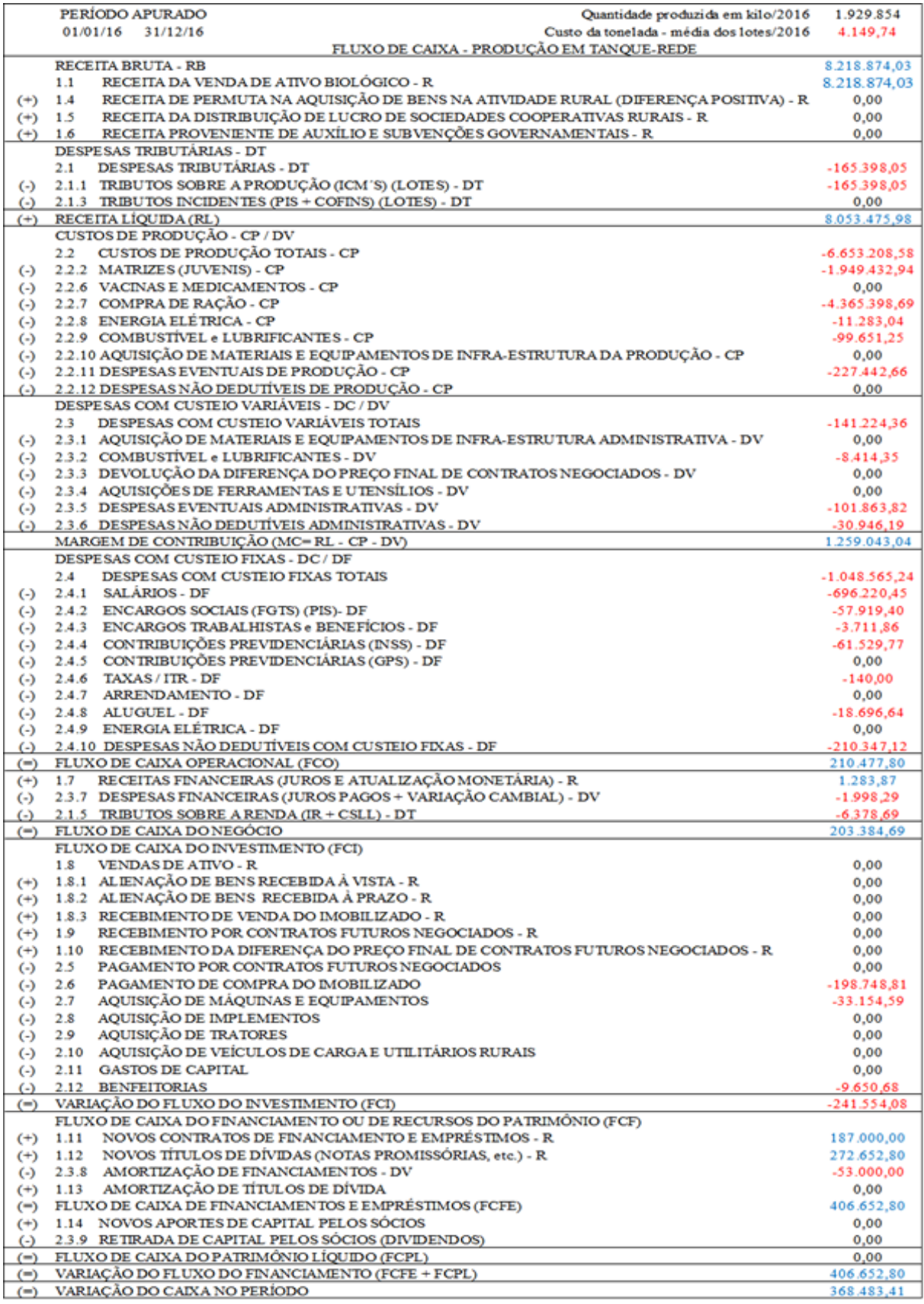

Figura 1. Fluxo de caixa sugerido para a piscicultura Fonte: CPC 03 (2010); Santos (2015). 


\subsection{RESULTADOS}

\subsubsection{Caracterização da atividade da empresa estudada}

O sistema produtivo de tilápias em tanques-rede, utilizado pelo produtor, compreende três fases de desenvolvimento sendo: 1) crescimento: que corresponde a alevinos de $1 \mathrm{~g}$ até $40 \mathrm{~g}$; 2) engorda: que corresponde a peixes com peso acima de $50 \mathrm{~g}$ até $350 \mathrm{~g}$; 3) terminação: peixes com 350g a 700g. Para uma produção de 10.000 unidades de tilápia são destinados 6 tanques utilizados nos três estágios ou fase do desenvolvimento.

Assim, para a fase 1 utiliza-se um único tanque-rede por até 45 dias, para a fase 2 são utilizados dois tanques com cerca de 4.200 peixes cada, levando o cultivo para 120 dias e, para a fase 3, são adotados seis tanques-rede com 1.300 peixes/ tanque, terminando o cultivo em 180 dias, no total.

O critério adotado para o povoamento dos tanques é o tamanho dos peixes e sua uniformidade. O arraçoamento é feito cinco vezes ao dia, sendo oferecida ração específica para cada estágio de desenvolvimento dos peixes.

A alimentação utilizada é de alta digestibilidade e excelente qualidade, associado a um programa alimentar eficiente, pois, além de reduzir a poluição do meio ambiente, contribui para o bom desempenho e saúde dos peixes.

\subsubsection{Resultado da gestão operacional}

Nos resultados apresentados, diante do exposto e discutido, entende-se que os objetivos foram atendidos, pois permitiram a caracterização e a análise do desempenho financeiro da empresa de piscicultura estudada por meio das variáveis sugeridas.

A empresa investigada é optante pela tributação como pessoa física. O grau de controle das informações financeiras da propriedade com base na estrutura do livrocaixa rural foi, portanto, a base de dados de onde foram extraídas e confeccionadas as variáveis propostas para esta análise.

O nível da informação existente para se efetuar a gestão financeira, a 
rentabilidade e a lucratividade era considerado incipiente, pois efetuava o confronto direto de receitas $\mathrm{x}$ custos/despesas.

O custo do quilo por peixe foi o fator principal destacado pelos produtores, como ponto de partida para se efetuar a análise da rentabilidade e da lucratividade.

\subsubsection{Resultado do desempenho financeiro}

Os eventos econômicos produzidos e coletados da empresa estudada, referentes ao exercício fiscal de 2016, apresentam os seguintes resultados, conforme ilustrado na Tabela 1.

Tabela 1. Resultados da empresa estudada

\begin{tabular}{lr}
\hline \multicolumn{2}{c}{ Resultados da empresa estudada } \\
\hline Faturamento anual (2016) & $8.218 .874,03$ \\
Média faturamento/ote & $684.906,17$ \\
Custos de Produção & $(6.653 .208,58)$ \\
Despesas com Custeio Variáveis & $(141.224,36)$ \\
Despesas com Custeio Fixas & $(1.048 .565,24)$ \\
\hline & \\
\hline Quantidade de peixes produzidos em 2016 em kilos & 1.929 .854 \\
Quantidade de peixes produzidos por lote em kilos (média 2016) & 160.821 \\
Custo da tonelada R\$/ton produzida por lote (média 2016) & $4.149,74$ \\
Preço de venda praticado por R\$/kilo (média 2016) & 4,26 \\
\hline
\end{tabular}

Fonte: Elaborado pelo autor.

Em um segundo momento foram obtidos os resultados do endividamento, liquidez e solvência: i) Retorno da margem de contribuição, é um dos indicadores financeiros mais importantes, sugere-se que este seja analisado regularmente, pois consegue-se visualizar exatamente como está a situação financeira da empresa (resultado do retorno da margem de contribuição da empresa estudada $=15,32 \%$ ); ii) Grau de alavancagem financeira, este índice demonstra que quanto maior for o GAF maior será seu endividamento e maior será seu risco (resultado do grau de alavancagem financeira $(\mathrm{GAF})=1,999)$; iii) Resultado do comprometimento do 
caixa com a dívida é um ótimo indicador da relação entre dívidas e recursos de uma empresa, ajudando a adicionar um pouco de contexto no valor bruto (resultado do comprometimento do caixa com a dívida da empresa estuda $=282,05 \%$ ); Cobertura de juros é um índice que mensura a capacidade de fazer pagamentos de juros contratuais, isto é, atender às obrigações contratadas (resultado apurado sobre a cobertura de juros da empresa estudada $=-105,3290)$.

Em um terceiro momento foram obtidos os resultados da rentabilidade da empresa estudada através: 1) do retorno do investimento (ROI), é o resultado esperado sobre o dinheiro investido, é preciso medi-lo e monitorá-lo constantemente (retorno do investimento da empresa estudada $=-87,13 \%$ ); 2) da margem operacional, demonstra como o resultado operacional da empresa está representado sobre a receita bruta (margem operacional da empresa estudada $=2,56 \%$ ); 3 ) $\mathrm{da}$ margem sobre a venda, é o percentual correspondente do lucro líquido sobre a receita bruta (margem sobre a venda da empresa estudada $=4,48 \%$; ) da margem líquida sobre um lote específico (lote nr 12) $=-8,59 \%$; 5 ) margem líquida de todos os lotes produzidos no exercício fiscal de $2016 \mathrm{da}$ empresa estudada $=65,25 \%$.

A proposição do modelo de gestão financeira para avaliar o desempenho da atividade de psicultura mostrou-se adequado à atividade, pois permite a avaliação dos resultados financeiros por lotes de produção e do agregado da propriedade, como demonstrado nos resultados já apresentados.

Além disso, a segregação dos custos desembolsáveis em fixos e variáveis, e o uso destes para o modelo, tornou este a base do fluxo de caixa o que proporciona uma avaliação e análise dos valores que efetivamente correspondem ao caixa do produtor e a geração de indicadores não enviesados com o regime de competência.

Entende-se, assim, que o modelo estende a análise restrita tradicional à atividade em que se considera, apenas, o fluxo de caixa do investimento. Nesse modelo, buscou-se agregar as demais dimensões financeiras da empresa como sua estrutura de endividamento e a gestão do capital de giro. A visão integrada desses principais processos da gestão financeira é fundamental para o processo de tomada de decisão, tendo em vista que há interdependência entre eles. 


\section{CONSIDERAÇÕES FINAIS}

Diante das especificidades do setor da psicultura, esse trabalho contribuiu com a proposição de uma metodologia que auxilie a gestão financeira do pequeno produtor rural nessa atividade econômica, apesar das limitações que restringem o avanço de propostas de modelos para a efetiva avaliação do desempenho financeiro em setores específicos, como a piscicultura, talvez uma causa principal possa ser apontada: a pequena preocupação científica no campo de desenvolvimento de modelos para a realização dessas análises.

Assim, é preciso reconhecer que avaliações desse tipo devem ser propostas para ações e contextos específicos. Nesse sentido, a proposta do modelo de gestão financeira na piscicultura considera, na sua essência, a necessidade de trabalhar as especificidades do setor, sendo estas tradicionalmente amparadas por informações de qualidade, desde sua coleta no registro dos eventos econômicos até sua posterior análise por meio dos indicadores sugeridos para essas empresas.

$\mathrm{Na}$ empresa estudada, uma "rotina" de procedimentos operacionais foi adotada em função da estratégia proposta, sendo assim, inicialmente, fez-se necessário a construção de um plano de contas único padronizado, para tal, utilizouse o plano já definido pela Receita Federal como modelo, que facilita a eventual utilização do Sistema Público de Escrituração Digital fiscal (SPED).

Foram efetuados lançamentos em rotina diária de todos os eventos econômicos produzidos pela empresa, que proporcionaram a medição do desempenho inicial através dos lotes de produção, além disso, implementouse os arquivos eletrônicos (CNAB) automáticos nas transações envolvendo dados eletrônicos produzidos, evitando assim erros e otimizando tempo.

Intencionou assim, com o modelo de gestão proposto e "rotina" de procedimentos, que a empresa consiga atingir seu objetivo de gerência com conservadorismo gerencial, porém, possa também projetar seus investimentos de curto, médio e longo prazo

Diante do exposto, defende-se que o aumento da profissionalização e da qualidade dos processos de gestão é premente diante de diversas limitações como informalidade, falta de capacitação técnica e de adequação do ambiente em que 
estão inseridas tais empresas. As dimensões e os indicadores que compõem uma avaliação da gestão financeira dificilmente podem ser estabelecidos sem uma devida compreensão do contexto real em que estão inseridos.

É importante assinalar que, apesar da informalidade dos registros, o contexto da produção da piscicultura, além de complexo, é rico de informações.

Em síntese, propõe-se, como modelo em seu resultado final, a governança dos seguintes indicadores: a) endividamento, composição do endividamento, estrutura de capital; b) liquidez corrente, liquidez seca, retorno sobre o ativo total (ROA), retorno sobre patrimônio (ROE), valor econômico adicionado (EVA); c) retorno da margem de contribuição, margem bruta, retorno sobre a venda; d) perfil da dívida, composição do endividamento, qualidade da alavancagem; e) qualidade da alavancagem do crédito de custeio, retorno da margem de contribuição; f) tangibilidade dos ativos, eficácia dos ativos, eficácia dos ativos dedicados, variação do investimento; g) ciclo financeiro, prazo médio de estocagem, prazo médio de recebimento, prazo médio de pagamento, necessidade de giro, equilíbrio financeiro; h) cobertura de juros, liquidação de financiamentos, margem EBIT; i) retorno sobre o investimento (ROI).

De posse desses indicadores, tanto os empresários rurais quanto os profissionais liberais que os assessoram podem criar uma sistemática para utilizálos de forma rigorosa e constante. Isto reduz em muito a necessidade de dados e oferece bases para o diálogo pragmático entre aqueles que detêm o saber das ciências contábeis e finanças e aqueles diretamente à frente das decisões produtivas, tomadas diariamente no campo da produção. Acresce-se que o aprendizado/utilização desses indicadores eleva a eficiência da gerência geral e oferece também uma avaliação mais crítica sobre as estratégias que envolvem a origem dos problemas e possíveis soluções.

Finalmente, há de se enfatizar a flexibilidade produtiva do agronegócio como um todo, logo, apesar de um estudo de projeto de investimento constituir uma referência importante, reside na gestão a capacidade de reduzir payback, elevar a margem de contribuição, estipular níveis de investimento compatíveis com o crescimento do mercado, adequar a relação investimento-liquidez e estabelecer poupança precaucionária diante da redução do grau de cobertura dos juros. 
Toda essa gestão é produtivo-financeira, e a possibilidade de implementação está em consonância com a realidade da tipologia de empresa rural com a qual o artigo pretende contribuir.

Espera-se que novas investigações nesta direção possam ser empreendidas como forma de avaliar a capacidade deste modelo em analisar as empresas da piscicultura por meio de pesquisas do tipo estudo de caso e pesquisa-ação. Estender essa abordagem para outros segmentos do agronegócio poderá contribuir de forma significativa para a gestão da empresa rural, cujo espaço na literatura é incipiente, apesar da relevante importância econômica e social que tem para o Brasil e para as economias emergentes.

\section{REFERÊNCIAS}

ALVES, K. L. F. Análise de sobrevivência de bancos privados no Brasil. 2009. 83f. Dissertação (Mestrado em Engenharia de Produção) - Escola de Engenharia de São Carlos, Universidade de São Paulo, São Carlos, Brasil, 2009.

ANYADIKE, C. C.; MBAJIORGU, C. C.; AJAH, G. N. Aquacultural System Management Tool (AQUASMAT) I: Model development. Aquacultural Engineering, Amsterdam, v. 69 , p. $60-77,2015$.

ASSAF NETO, A. Finanças corporativas e valor. 5. ed. São Paulo: Atlas, 2009. 824p.

AZEVEDO, R. V. D.; FOSSE FILHO, J. C.; CARDOSO, L. D.; MATTOS, D. C.; VIDAL JÚNIOR, M. V.; ANDRADE, D. R. Economic evaluation of prebiotics, probiotics and symbiotics in juvenile Nile tilapia. Ciência Agronômica, Fortaleza, v. 46, n. 1, p. 72-79, 2015.

CONFORTO, E. C.; AMARAL, D. C.; SILVA, S. L. D. Roteiro para revisão bibliográfica sistemática: aplicação no desenvolvimento de produtos e gerenciamento de projetos. In: CONGRESSO BRASILEIRO DE GESTÃO DE DESENVOLVIMENTO DE PRODUTO, 8., 2011, Porto Alegre. Anais [...]. Porto Alegre: IGDP, 2011. 1 CD-ROM.

CORRÊA, R. G. D. F.; KLIEMANN NETO, F. J.; DENICOL, J. Revisão de proposições para a gestão econômico-financeira de sistemas produtivos agropecuários: a inter- 
-relação entre fluxo de caixa, sistemas de custos e recursos compartilhados. Custos e @gronegócio on Line, Recife, v. 12, n. 1, p. 113-141, 2016.

CPC 03. Comitê de Pronunciamentos Contábeis (R2). Demonstração dos Fluxos de Caixa. Brasília, 2010. (Correlação às Normas Internacionais de Contabilidade IAS 7 (IASB - BV 2010)).

DAMODARAN, A. Investment valuation: tools and techniques for determining the value of any asset. New Jersey: John Wiley \& Sons, 2012. 922p.

DE BEZERRA, T. R. Q.; DOMINGUES, E. C.; MAIA FILHO, L. F. A.; ROMBENSO, A. N.; HAMILTON, S.; CAVALLI, R. O. Economic analysis of cobia (Rachycentron canadum) cage culture in large and small-scale production systems in Brazil. Aquaculture International, Dordrecht, v. 24, n. 2, p. 609-622, 2016.

DOMÍNGUEZ-CASTANEDO, O.; TOLEDANO-OLIVARES, Á.; MARTÍNEZ-ESPINOSA, D.; ÁVALOS-RODRÍGUEZ, A. Cambios morfológicos en gametos del barbo tigre Puntius tetrazona (Cypriniformes: Cyprinidae) e implementación de la fertilización in vitro. Revista de Biología Tropical, San Jose, v. 62, n. 4, p. 1353-1363, 2014.

EL-SAYED, A.-F. M.; DICKSON, M. W.; EL-NAGGAR, G. O. Value chain analysis of the aquaculture feed sector in Egypt. Aquaculture, Amsterdam, v. 437, p. 92-101, 2015.

EMERY, J. A.; SMULLEN, R.; KEAST, R. S. J.; TURCHINI, G. M. Viability of tallow inclusion in Atlantic salmon diet, as assessed by an on-farm grow out trial. Aquaculture, Amsterdam, v. 451, p. 289-297, 2016.

FARIA, R. B. D.; SANTOS, D. F. L. O crédito rural no Brasil: o perfil das pesquisas acadêmicas. Revista Gestão e Desenvolvimento, Novo Hamburgo, v. 11, n. 2, p. 148-165, 2014.

FRANÇA, I.; PIMENTA, P. P. P. A viabilidade da piscicultura para o pequeno produtor de Dourados. Comunicação \& Mercado/UNIGRAN, Dourados, v. 01, n. 01, p. 3651, 2012.

GIL, A. C. Como elaborar projetos de pesquisa. 4. ed. São Paulo: Atlas, 2002. 176p. 
GODOY, A. S. Introdução à pesquisa qualitativa e suas possibilidades. Revista de Administração de Empresas, São Paulo, v. 35, n. 2, p. 57-63, 1995.

GONZÁLEZ, M. O. A.; TOLEDO, J. C. D. A integração do cliente no processo de desenvolvimento de produto: revisão bibliográfica sistemática e temas para pesquisa. Gestão \& Produção, São Carlos, v. 22, n. 1, p. 14-26, 2012.

MACFADYEN, G.; NASR-ALLA, A. M.; AL-KENAWY, D.; FATHI, M.; HEBICHA, H.; DIAB, A. M.; HUSSEIN, S. M.; ABOU-ZEID, R. M.; EL-NAGGAR, G. Value-chain analysis - An assessment methodology to estimate Egyptian. Aquaculture, Amsterdam, v. 362363, p. 18-27, 2012.

MATIAS, A. B. Finanças corporativas de cutro prazo. São Paulo: Atlas, 2007.312p.

PIGOSSO, D. C. A.; ROZENFELD, H. Métodos e ferramentas de Ecodesign: revisão bibliográfica sistemática. Produto \& Produção, São Carlos, v. 13, n. 1, p. 16-33, 2012.

SANTOS, D. F. L. Modelo de gestão financeira aplicada em empresa do setor de construção civil. Tecnologias de Administrração e Contabilidade, Rio de Janeiro, v. 5, n. 2, p. 119-135, 2015.

SECRETARIA DA RECEITA FEDERAL DO BRASIL. Secretaria da Receita Federal do Brasil. 2017. Disponível em: http://idg.receita.fazenda.gov.br/. Acesso em: 3 mar. 2017.

WEBSTER, J.; WATSON, R. T. Analyzing the past to prepare for the future: Writing a literature review. MIS Quarterly \& The Society for Information Management, Minneapolis, v. 26, n. 2, p. 13-23, 2002.

Recebido em: 25/07/2017

Aceito em: 20/02/2019 